Puede citar este artículo como:

Carrasco Manchado, Ana Isabel. «La invención de la política en el siglo XII: reflexiones y propuestas desde una perspectiva conceptual». Anales de la Universidad de Alicante. Historia Medieval, N. 19 (2015-2016): 41-65, DOI:10.14198/medieval.2015-2016.19.02

\title{
LA INVENCIÓN DE LA POLÍTICA EN EL SIGLO XII: REFLEXIONES Y PROPUESTAS DESDE UNA PERSPECTIVA CONCEPTUAL
}

\author{
Ana Isabel Carrasco Manchado ${ }^{1}$ \\ Universidad Complutense de Madrid
}

\section{RESUMEN}

Este trabajo tiene un doble objetivo. El primero, subrayar la conveniencia de adoptar la perspectiva conceptual de Reinhart Koselleck, y otras propuestas vinculadas a la semántica histórica, para estudiar las realidades políticas medievales. Tópicos historiográficos, como el de cultura política, pueden ser mejor entendidos guiándose por la perspectiva conceptual y sometiendo a crítica la propia noción de 'política', despojándola de los significados actuales. El segundo objetivo pretende la aproximación al concepto de 'política' en el siglo XII, a través de un recorrido por la adopción e impulso de la palabra 'política' en la cultura medieval y su uso por autores como Juan de Salisbury. Apoyaremos la tesis de la politización del poder en el siglo XII y de la formación de una cultura política paralela. Es el punto de partida para una mejor comprensión de los cambios institucionales en las relaciones de poder que se producirán durante los siglos XIII al XV.

Palabras clave: Cultura política; Siglo XII; Macrobio; Juan de Salisbury; Politización.

1 Doctora en Historia. Profesora Titular. Departamento de Historia Medieval. Facultad de Geografía e Historia. Universidad Complutense de Madrid. Avda. Profesor Aranguren s/n. 28040 Madrid. C.e.: aicarras@ghis.ucm.es. Este trabajo se enmarca en el proyecto de investigación «Nuevos métodos para la Historia social y política de la Edad Media hispánica: aplicaciones históricas de los corpus textuales informatizados», MINECO, HAR 2010-17860. 


\section{ABSTRACT}

This paper has two objectives. First, in order to emphasize the need for promote conceptual perspective Reinhart Koselleck and other proposals that emphasizes the need to use linguistic methods to study medieval political realities. Historiographical topics, such as 'political culture' can be better understood guided by the conceptual perspective and subjected to review the notion of 'politica', stripping current meanings. Second, we will approach the concept of 'politica' in the twelfth century, a journey through the adoption and promotion of the word 'politica' in medieval culture and its use by authors like John of Salisbury. We will support the thesis of the politicization of power in the twelfth century and the formation of a parallel political culture. It is the starting point for a better understanding of the institutional changes in the relations of power that will occur during the thirteenth and fifteenth centuries.

Keywords: Political culture; Twelfth century; Macrobius; John of Salisbury; Politicization.

Desde hace un tiempo se viene llamando la atención sobre la falta de adecuación de los conceptos contemporáneos a las épocas preindustriales: el concepto de "política" sería uno de ellos². No ha cambiado la forma de la palabra, pero sí, en cambio, su contenido semántico. ¿Se conocía en los siglos medievales la experiencia política tal y como la entendemos hoy en día? Cuando reaparece la palabra política, ¿qué sentidos adquirió?; ¿qué nos dice acerca de los cambios sociales su evolución semántica? Estas preguntas no deberían parecer absurdas ni inoperantes para el historiador.

En este trabajo pretendemos apoyar la hipótesis de que la Edad Media no conoció la política, en el sentido predominante que hoy tiene el concepto, pero sí descubrió y elaboró su propio sentido de política. Por ello hemos titulado este trabajo la "invención" de la política”, porque, si bien fueron los griegos los que legaron la palabra con su contenido semántico, tal palabra y significado quedaron prácticamente olvidados al desvanecerse el mundo antiguo, para volver a ser hallados en el transcurso de los siglos medievales. Desde este punto de vista puede hablarse de innovación conceptual, en relación con la política, innovación que fue puesta al servicio de la acción. Pero, antes

2 GUERREAU, A., «Política/Derecho/economía/religión», en Pastor R. (comp.), Relaciones de poder, de producción y parentesco en la Edad Media y Moderna, Madrid, 1990, pp. 459-465.

3 "Invención", del latín inventio, "vale lo mismo que hallazgo", Diccionario de la lengua castellana, Madrid, RAE, 1734. 
de afrontar la cuestión, nos ha parecido necesario explicitar la perspectiva teórica en la que se apoya esta hipótesis, que es la conveniencia de asumir los planteamientos de la historia conceptual como vía para someter a crítica la práctica historiográfica consistente en emplear nociones contemporáneas (tales como la propia noción actual de política) en el análisis de la sociedad medieval, y, en concreto, en los análisis dentro de ese ámbito de la historia que (precisamente) ha venido llamándose historia política.

Para llevar a cabo nuestros objetivos sería necesario, primero, deconstruir el concepto de política desde nuestra época y, después, reconstruirlo tal y como se fue entendiendo en la Edad Media, para tratar así de reubicar su sentido en la estructura social y en el sistema de representaciones medievales. Esta tarea, claro está, es demasiado ardua como para poder ser abordada en un solo trabajo. Ya en otro trabajo previo destacamos la utilización novedosa en la Corona de Castilla de la forma verbal 'politizar', calco del neologismo latino 'politizare', cuyo uso comienza a ser frecuente en el siglo $\mathrm{XV}^{4}$. Pensamos que estas innovaciones lingüísticas son un indicio del proceso de politización que se experimenta en toda Europa a lo largo de la Edad Media. Para tratar de seguir comprendiendo este fenómeno haremos ahora otra aproximación a esta problemática, retrotrayéndonos a los inicios del proceso de politización, que puede datarse en el siglo XII, fijándonos en cómo se usaba el vocablo 'política' y sus variantes, antes de la recepción de la Política de Aristóteles5.

4 CARRASCO MANCHADO, A. I., «Análisis de las fuentes literarias castellanas para la historia de la cultura política en la Edad Media: el ejempo de 'política', 'políticos', 'politizar'», en Fernández López, Mª C., Suárez Fernández, A. y Veiga, A. (eds.), ¡Oh lux Iberiae! En torno a las letras en la España Medieval, Lugo, 2013, pp. 181-201. Rodrigo Sánchez de Arévalo empleaba la palabra 'politizar' con asiduidad. Agradezco a Luis Fernández Gallardo el haberme indicado que el maestro de Arévalo, Alfonso de Cartagena, ya había usado antes que él ese neologismo en latín ('modus politizandi'), en el Duodenarium (le agradezco también el haberme facilitado el fragmento correspondiente de esta obra, cuya edición y traducción está preparando, junto a Teresa Jiménez Calvente).

5 La metodología de este trabajo se apoya en el uso de herramientas de procesamiento de datos lingüísticos. En concreto, además de incluir las menciones que hemos hallado en las propias fuentes o en la bibliografía, hemos manejado los recursos (listas de palabras, frecuencias, concordancias, ediciones digitales, etc.) que proporciona BÄNZIGER, M., Monumenta Informatik. Así, salvo alusión en contra, las citas (con indicación de las ediciones entre paréntesis) proceden de Monumenta Informatik. http:// monumenta.ch/latein/advkonkordanz.php? suchbegriff $2=$ politic* $\&$ binary=true\&modi $\mathrm{f}=\&$ domain $=\&$ lang $=0 \&$ tabelle $=$ Latein $\&$ id $=\& \mathrm{k}$ kwlaus $=\mathrm{kk} \_$alle $\&$ von $=$ advsuchen $\&$ suc hbegriff=politic*\&target $=$ [búsqueda 'politic*'], (Consulta: 2/6/2014). De este modo, ofrecemos una aplicación concreta de los resultados del proyecto «Nuevos métodos para la Historia social y política de la Edad Media hispánica: aplicaciones históricas de los corpus textuales informatizados», MINECO, HAR2010-17860. 


\section{LA PERSPECTIVA CONCEPTUAL}

Entre las tareas del historiador se encuentra la de clarificar el sentido de los conceptos sobre los que fundamenta sus interpretaciones o tentativas de explicación del pasado. Los historiadores de la Edad Media, queriendo perfeccionar nuestras teorías, aunque también, en ocasiones, por influjo de motivos ideológicos, hábitos profesionales adquiridos o, incluso, por seguir ciertas modas, recurrimos a nociones que pueden terminar cayendo en el anacronismo. Esto no ocurre solo con nociones complejas tomadas de las ciencias sociales, sino con otras que forman parte de nuestra propia experiencia social, muchas de las cuales han sido casi naturalizadas por un discurso historiográfico forjado a lo largo de más de dos siglos de razonamiento histórico. La equivalencia con nuestro universo mental y social es engañosa. Cualquier profesor de historia medieval sabe lo difícil que es tratar de que sus estudiantes neófitos en la materia entiendan que nociones como 'familia', 'trabajo', 'individuo', o, incluso, 'sexualidad'9 $\mathrm{o}$ 'arte'10, no existían como tales en la Edad Media. A la hora del análisis, una opción es asumir el anacronismo de determinado concepto ${ }^{11}$, aclarando en qué medida puede adaptarse a una época tan distinta y alejada de la nues-

6 GUERREAU-JAlaberT, A., «Parentesco», en Le Goff, J. y Schmitt, J. C., Diccionario razonado del Occidente medieval, Madrid, 2003, 626-627, sobre las connotaciones de 'familia' en el siglo XIX.

7 Le Goff advirtió que el significado actual de 'trabajo' procede del siglo XIX: LE GOFF, J., «Trabajo», en ibídem, p. 781-782.

8 En todas las épocas habría habido hombres y mujeres, pero no individuos (esto es, conscientes de su individualidad y dispuestos a la auto-representación): GOUREVITCH, A., «Individuo», ibídem, p. 383 y BEDOS-REZAK, B. M., y IOGNA-PRAT, D. (eds.), Lindividu au Moyen Âge. Individuation et individualisation avant la modernité, París, 2005.

9 Los historiadores de la sexualidad se refieren a las épocas premodernas como épocas en las que existe el sexo antes de existir la sexualidad, de manera que no tiene sentido ni realidad, en sociedades anteriores a la contemporánea, nociones como 'heterosexualidad' u 'homosexualidad': HALPERIN, D. M., «Is There a History of Sexuality?», en Abelove, H., Barale, M. A., y Halperin, D. M. (eds.), The Lesbian and Gay Studies Reader, Nueva York-Londres, 1993, pp. 416-431; PHILLIPS, K. M., y REAY, B. (eds.), Sex Before Sexuality: a Premodern History, Cambridge, 2011.

10 La historia de las imágenes, más cerca de la función de las imágenes en la Edad Media, ha sustituido a la tradicional "Historia del arte", en la que se proyectaba 'nuestra' visión del arte: SCHMITT, J.C., «Imágenes», en Le Goff, J. y Schmitt, J. C., Diccionario razonado, p. 365 .

11 Es el problema de la alternativa entre "categorías anacrónicas" y "categorías historiográficamente operativas", ya planteado, por ejemplo, por MONSALVO ANTÓN, J. M., «Historia de los poderes medievales. Del derecho a la Antropología. El ejemplo castellano: monarquía, concejos y señoríos en los siglos XII-XV», en Barros, C., Historia a debate, vol. IV, Santiago de Compostela, 1995, pp. 95-96. 
tra ${ }^{12}$. Pero, aún así, de algún modo, ¿no condiciona su empleo la visión que ofrecemos del pasado medieval? La Edad Media tiende a volverse entonces un mundo demasiado parecido a nuestra época contemporánea. Esa perspectiva "presentista" puede imposibilitarnos para percibir los cambios específicos y propios que caracterizan la sociedad medieval ${ }^{13}$. Entre la intuición de Bloch de que "toda historia es historia contemporánea", y el planteamiento "levi-straussiano" de Jaques Le Goff ("el pensamiento medieval tiene sus razones"), hay un inestable equilibrio que mantener.

No hace mucho que Alain Guerreau avisaba del riesgo para el historiador de la Edad Media de abusar de los "macroconceptos" y de la necesidad de emprender una renovación conceptual en el análisis histórico ${ }^{14}$. Desde una visión estructural de la historia de Occidente, Guerreau considera la sociedad medieval como un conjunto jerarquizado de relaciones, entre las que se encuentran las relaciones de significado. Toda sociedad contiene una estructura semántica, un sistema de representaciones que puede ser desvelado mediante el análisis del lenguaje ${ }^{15}$. Vale la pena sintetizar su conocida tesis. Al llegar el siglo XVIII se produce una ruptura de la estructura social, de tal manera que los dos pilares que habían conformado y configurado la sociedad medieval, la ecclesia y el dominium, serán sustituidos por otras nociones que conformarán la nueva estructura social de la modernidad imperante a partir de entonces. La consecuencia de esta "doble fractura conceptual" es que la vieja sociedad

12 Cuando empecé a investigar sobre propaganda política en la Edad Media, puesto que la palabra no se usaba en la época medieval, lo primero que hice fue tratar de averiguar con qué palabras nombrarían en aquellos siglos 'eso' que podría entenderse como 'propagandístico': CARRASCO MANCHADO, A. I., «Aproximación al problema de la consciencia propagandística en algunos escritores políticos del siglo XV», En la España Medieval, 21 (1998), pp. 229-269. Pero, aunque sea razonable plantear la hipótesis de la existencia de la propaganda política en la Edad Media, el problema sigue existiendo: 'eso propagandístico' que buscamos, ¿no lo será desde nuestra concepción de la propaganda política?

13 Sobre el presentismo en la escritura de la historia, BENIGNO, F., Las palabras del tiempo. Un ideario para pensar históricamente, Madrid, 2013. Benigno disecciona los conceptos de 'identidad', 'generaciones', 'cultura popular', 'violencia', 'poder', 'Estado moderno', 'revoluciones', 'opinión pública' y 'Mediterráneo'.

14 GUERREAU, A., El futuro de un pasado. La Edad Media en el siglo XXI, Barcelona, 2002. Comenta las controvertidas tesis de Guerreau, ASTARITA, C., "Las tesis de Alain Guerreau», Edad Media. Revista de historia, vol. 6 (2003), pp. 183-207.

15 Entre las disciplinas sociales útiles para renovar la historia, Guerreau propone la semántica histórica. Algunos de sus recientes trabajos metodológicos, GUERREAU, A., " Pour un corpus de textes latins en ligne», Bulletin du centre d'études médiévales d'Auxerre (2011), URL: http://cem.revues.org/11787; y "Textes anciens en série », Bulletin du centre d'études médiévales d'Auxerre (2012), URL: http://cem.revues.org/12177; (Consulta: 28/5/2014). 
será percibida (con distintos fines legitimadores de la nueva sociedad) desde las claves que definen esa nueva sociedad: desde la 'política', la 'economía', la 'religión' ${ }^{16}$. Sobre esta ruptura, al hilo del desarrollo científico de la historia (también creación de finales del siglo XVIII), se han edificado artificiales compartimentos casi estancos que han delimitado la Historia política, la Historia de la Iglesia, la Historia de la Economía, con sus abanicos de nociones y conceptos descontextualizados, y la subsiguiente difuminación de la perspectiva social global. La propuesta de Guerreau es, en definitiva, recomponer la imagen global y estructurada de la sociedad medieval y tomar conciencia de esa ruptura conceptual y de cómo nacen y se utilizan los conceptos (o 'macroconceptos') con los que construimos la historia de la Edad Media, reducir su uso al mínimo y tratar de entender y manejar los conceptos propios emanados del sistema de representación medieval.

La propuesta de Guerreau se inspira en parte en las teorías elaboradas por el historiador alemán Reinhart Koselleck, impulsor de la historia conceptual. La tarea de Koselleck ha sido la de investigar los conceptos sociales y políticos que han gestado la modernidad occidental, partiendo de la idea de que los cambios sociales y políticos que se produjeron entre 1750 y 1850 se vieron acompañados de una gran mutación intelectual (Sattelzeit); la mayoría de los conceptos tradicionales cambiaron entonces de sentido (orientándose hacia nuevas "expectativas de futuro" ${ }^{17}$. La lección teórica de Koselleck y de sus colaboradores (Otto Brunner, Werner Conze) a través de la creación del Archivo para la historia conceptual, que dio lugar al diccionario de los conceptos históricos fundamentales (Geschichtliche Grundbegriffe-GG-), ${ }^{18}$ es que cualquier término al que damos un significado social o político no puede ser comprendido fuera de la estructura social, económica y política que lo genera y que todo término aparece recubierto de capas de significados forjados a lo largo del tiempo, teniendo en cuenta, además, que la concepción misma de 'tiempo', y las expectativas que genera, han experimentado también trasformaciones ${ }^{19}$. Comprender un concepto supone separar todos esas

16 GUERREAU, A., El futuro de un pasado, pp. 19-47.

17 PALTI, E., J., «Koselleck y la idea de Sattelzeit: un debate sobre modernidad y temporalidad», Ayer, 53 (2004), 63-74. El análisis de Koselleck se centra en Alemania, no en toda Europa, ya que el estudio de los conceptos está influenciado por la lengua que los formula.

18 Diccionario de Conceptos Fundamentales Políticos y Sociales en Lengua Alemana. BRUNNER, O., CONZE, W. y KOSELLECK, R., (dir.), Geschichtliche Grundbegriffe: Historisches Lexikon zur politisch-sozialen Sprache in Deutschland, Sttutgart, 19921997. El primer volumen fue publicado en 1972.

19 Véase para esta problemática KOSELLECK, R., Futuro pasado. Para una semántica de los tiempos históricos, [1979], Barcelona, 1993. 
capas, es decir, realizar una tarea de reconstrucción histórica. Si Koselleck y sus colaboradores lograron identificar ese momento de mutación conceptual, cabe pensar que dicha mutación no fue la única producida en la historia. De manera que estamos autorizados a investigar en el pasado y, en concreto, en el pasado medieval, los momentos clave de transformación conceptual, ya sean entre la Antigüedad y la Edad Media, o entre los siglos XV y XVI ${ }^{20}$. El problema reside en dar con los métodos adecuados para estudiar las realidades conceptuales medievales.

En España, las propuestas de Koselleck y de sus colaboradores han tenido una acogida expresa por parte de los historiadores contemporaneístas, dando lugar a proyectos importantes ${ }^{21}$. Comienzan también a ser valoradas entre los modernistas ${ }^{22} \mathrm{y}$, de forma más bien escasa, por los historiadores medievalistas $^{23}$, a pesar de que uno de los autores del GG, el austriaco Otto Brunner, fue uno de los historiadores de la Edad Media más influyentes en Alemania ${ }^{24}$. Dejando a un lado la discutida orientación ideológica de los

20 Uno de los indicios del cambio en esos siglos sería el "momento maquiavélico", expresión ideada por Pocok para explicar el modo en que los florentinos trataron de conciliar su ideal de permanencia de la República con la inexorable caducidad de toda construcción política humana, según la concepción tradicional de la historia en el cristianismo, (POCOCK, J., El Momento maquiavélico. El pensamiento político florentino y la tradición republicana atlántica, [1975], Madrid, 2002).

21 FERNÁNDEZ SEBASTIÁN, J., Y FRANCISCO FUENTES, J. (dirs.), Diccionario politico y social del siglo XIX español, Madrid, 2002; y, de los mismo directores, Diccionario político y social del siglo XX español, Madrid, 2008. FERNÁNDEZ SEBASTIÁN, J. (dir.), Diccionario político y social del mundo iberoamericano. La era de las revoluciones, 1750-1850. Iberconceptos-I, Madrid, 2009. Javier Fernández Sebastián dirige el grupo Historia intelectual de la política moderna. Lenguajes, conceptos y discursos, en la Universidad del País Vasco.

22 Ricardo García Cárcel, en el prólogo a la obra de BENIGNO, F., Las palabras del tiempo, pp. 11-25. Algunas utilizaciones: SUÁREZ VARELA, A., «La conjuración comunera. De la antigua germanitas a la confederación de Tordesillas», Historia, Instituciones y Documentos, 34 (2007), p. 256, a propósito de la noción de 'hermandad' como forma de pacto consociativo y, del mismo autor, "Celotismo comunal. La máxima del procomún en la revuelta comunera», Tiempos modernos, 5, 15 (2007) http://www.tiemposmodernos.org/tm3/index.php/tm/article/downloadSuppFile/92/15. (Consulta: 9/6/2014), p. 1 y 5, sobre la necesidad de abordar la máxima a la luz de una historia conceptual.

23 DIAGO, M., «El perfil socioeconómico de los grupos gobernantes en las ciudades bajomedievales: análisis comparativo de los ejemplos castellanos y alemán», En la España Medieval, 18 (1995), pp. 85-88; siguiendo la sugerencia de Otto Brunner de no aplicar las categorías sociales decimonónicas al análisis de la sociedad medieval, Diago criticaba el uso de 'burguesía' y 'patriciado' para nombrar a los gobernantes de las ciudades castellanas.

24 Julien Demade ha escrito que Otto Brunner fue, quizá, el medievalista alemán más influyente y renovador hasta 1982 (el "equivalente a Marc Bloch en Francia"), impul- 
análisis de Brunner ${ }^{25}$, sus métodos y algunas de sus tesis siguen teniendo vigencia $^{26}$, en tanto que critican el uso de categorías decimonónicas para caracterizar la estructura política medieval, entre ellas la noción de Estado (esto es, la noción de Estado Moderno) ${ }^{27}$, promoviendo así el estudio de la Edad Media desde su propia estructura conceptual.

La historia conceptual, tal y como se ha venido desarrollando, no está exenta de críticas. Se le ha cuestionado, por ejemplo, las fuentes empleadas, pues Koselleck y sus colaboradores tendían a centrarse en los grandes testimonios del pensamiento o de la cultura intelectual, y dejaban a un lado otras fuentes más cercanas al uso cotidiano. También se les ha cuestionado el ordenamiento en forma de diccionario, un formato cerrado, o la falta de conexión con otras aproximaciones semánticas más dinámicas ${ }^{28}$, como las que se ocupan del análisis del discurso, que tienden a analizar el lenguaje político de forma más amplia (no centrándose solo en conceptos sino en enunciados o, incluso, en actos de habla). Figuras clásicas de esta otra corriente discursiva o ideológica, como J. G. A. Pocock o Quentin Skinner han entrado en diálogo con la historia conceptual ${ }^{29}$. Con la creación (en 1998), del History

sor, tras la guerra, de la historia estructural o social. Excluido de la universidad entre 1945 y 1955, por su adhesión al nazismo, fue reincorporado en los años 50', llegando, incluso, a ejercer de rector en la universidad de Hamburgo en 1959. DEMADE, J., «El mundo rural medieval en la historiografía en alemán desde 1930. Compromiso político, permanencia de las interpretaciones y dispersión de las innovaciones», en Alfonso, I., La historia rural de las sociedades medievales europeas: tendencias y perspectivas, Madrid, 2008, pp. 175-246 (versión digitalizada, halshs-00331855, versión 1-18 de oct. 2008 , p. 6 , n. 20 y p. 46).

25 Destaca Demade que, tras la guerra, solo Fernand Braudel planteó cierta sospecha en relación con su visión admirativa del Antiguo Régimen (ibídem, p. 39, n. 45).

26 Sobre la recepción de Brunner entre los impulsores de la antropología jurídica, Manuel A. Hespanha o Bartolomé Clavero, SANJURJO DE DRIOLLET, I., «La pionera obra de Otto Brunner a través de sus comentaristas», Revista de historia del derecho, 42 (2011), pp. 155-170.

27 En su obra Land und Herrschaft (escrita en 1939, y revisada ideológicamente por él mismo en 1959), Brunner indicaba que la noción de 'Estado', concepto que se corresponde con el mundo político moderno -el Estado liberal-, pasó a convertirse en un 'superconcepto' que servía para caracterizar cualquier modelo de convivencia ordenada de la unidad política, independientemente del período histórico que se analizara. De ese modo, el concepto, perdía su historicidad. BRUNNER, O., Terra e potere, Milán, 1983, pp. 157-228.

28 Véase la introducción de Antonio Gómez Ramos a su traducción de KOSELLECK, R., historia/Historia, Madrid, 2004, pp. 19-20.

29 Sobre la dinámica concepto/discurso: POCOCK, J. G. A., «Concepts and Discourses: A Difference in Culture? Comment on a Paper by Melvin Richter», en Lehmann H., y Richter M. (ed.), The Meaning of Historical Terms and Concepts: New Studies on Begriffsgeschichte, Washington, 1996, pp. 47-58 (http://www.ghi-dc.org/publications/ ghipubs/op/op15.pdf, (Consulta: 31/5/2014). Sobre las diferentes perspectivas en 
of Political and Social Concepts Group, y, recientemente, en 2012, del History of Concepts Group, la historia conceptual está ampliando y enriqueciendo sus perspectivas iniciales ${ }^{30}$.

Una crítica más profunda apunta a la intención, al paradigma ideológico subyacente de esta tendencia aplicada al análisis de la época premoderna: al asumir la terminología de las clasificaciones sociales propias de esta época (con órdenes, estamentos, privilegios), nos quedaríamos en un nivel descriptivo de la sociedad tal y como se nos presenta, lo cual nos llevaría, de alguna manera, a adoptar ese mismo punto de vista social, dejando a un lado las tensiones, los conflictos, las discrepancias ideológicas ${ }^{31}$. Sería una forma de naturalizar esas categorías sociales que representan el orden social, como tiende a hacer la sociología funcionalista. No obstante, cabe pensar que estos riesgos ideológicos son salvables, si partimos de la premisa de que no es posible estudiar la sociedad, ya sea presente o pasada, sin abordar conjuntamente orden y conflicto.

En conclusión: si los conceptos sociales y políticos más relevantes de la modernidad española han sido estudiados con el objetivo de comprender mejor los cambios producidos al llegar los siglos XIX y XX, sería lógico continuar esta reconstrucción hacia atrás en el tiempo. Para el medievalista, además, se plantea un triple reto de análisis histórico: el del vocabulario medieval, el de las nuevas palabras y/o nuevos significados que mutaron en el siglo XIX y que fueron empleadas para representar la Edad Media (y que han seguido evolucionado en el xx y están cambiando en el xxI) y, finalmente, las categorías inventadas por los propios historiadores.

Para emprender esta tarea contamos hoy en día con suficientes teorías y métodos: desde las clarividentes advertencias de Marc Bloch, que nos

torno al lenguaje político que sostienen la escuela británica y la escuela alemana, en este mismo volumen, véase RICHTER, M., «Appreciating a Contemporary Classic: The Geschichtliche Grundbegriffe and Future Scholarship», pp. 7-19 y la respuesta del propio Koselleck, KOSELLECK, R., "A Response to Comments on the Geschichtliche Grundbegriffe», pp. 59-70.

30 BLANCO RIVERO, J. J., «La historia de los conceptos de Reinhart Koselleck: conceptos fundamentales, Sattelzeit, temporalidad e histórica», 35 (Julio-Diciembre) Politeia (2012), pp. 1-35, http://www.redalyc.org/articulo.oa?id=170029498009. (Consulta: 31/5/2014). Véase el portal del grupo: Contributions to the history of concepts, http:// www.historyofconcepts.org.

31 Es la crítica que hace BENIGNO, F., Las palabras del tiempo, pp. 62-63 al trabajo, en concreto, de Brunner (aunque no a la historia conceptual). VAN HORN MELTON, J., "Otto Brunner and the ideological origins of Begriffsgeschichte, en Lehmann H., y Richter M. (ed.), The Meaning of Historical, pp. 21-33, advierte de que las críticas que se han hecho a la posición de Brunner no conviene extenderlas a Koselleck ni al Geschichtliche Grundbegriffe. 
invitaban a tomar en serio, al abordar el análisis histórico, los problemas derivados de la terminología histórica ${ }^{32}$, pasando por la historia conceptual, la semántica histórica y otras orientaciones centradas en la necesidad de comprender el lenguaje en su sentido histórico ${ }^{33}$, estén o no ligadas a las propuestas del llamado "giro lingüístico", también hoy en día revisado y sometido a crítica ${ }^{34}$.

\section{EL HALLAZGO DE LA POLÍTICA EN LA EDAD MEDIA}

En la Edad Media se redescubre la política, pero no la política tal y como se entenderá en el mundo contemporáneo. Los autores que empleaban la palabra en el siglo XII, antes de la traducción latina de la Política de Aristóteles, que supuso un incremento decisivo en el uso del vocablo y sus derivados, fueron incorporando a su universo conceptual algunos de los significados antiguos de la palabra, significados que acomodaron a su propia realidad, tan distinta de la antigua. Este proceso cognitivo, favorecido por la labor de traducción, resulta muy interesante, pues se trataba de encontrar palabras nuevas para nombrar realidades abstractas, como eran las relaciones sociales, en un momento en el que parecía que las palabras de la tradición cristiana no bastaban. Esa inquietud por asignar nombres nuevos (tomados de moldes antiguos) para caracterizar y describir la sociedad -ya sea en un sentido real o ideal- acompañó al proceso de politización que, según se ha afirmado ${ }^{35}$, comenzó a percibirse en torno al año 1200.

Este momento de politización constituye una novedad en la Edad Media y debe verse como un síntoma de los cambios más profundos en las rela-

BLOCH, M., Introducción a la historia, Madrid, 1988, pp. 121-145.

33 Ensayar con diversos métodos lingüísticos en diferentes aplicaciones históricas ha sido objetivo prioritario del proyecto que iniciamos en 2010 (MINECO HAR201017860). Para ciertos temas actuales de la historia política, relacionados además con la historia cultural, resulta imprescindible emplear estos métodos: véase, por ejemplo, FORONDA, F., El espanto y el miedo. Golpismo, emociones políticas y constitucionalismo en la Edad Media, Madrid, 2013, obra que reúne investigaciones previas que el autor sustentó en recursos lexicométricos utilizados en el LAMOP, junto con otras en las que empleó las herramientas con las que hemos estado trabajando en el marco del proyecto mencionado.

34 Propuestas que, en el siglo XXI, suponen no centrarse exclusivamente en el texto, sino conectar este con la acción; SPIEGEL, G., «La historia de la práctica: nuevas tendencias en historia tras el giro lingüístico», Ayer 62/2006 (2), pp. 19-50.

35 Thomas Bisson es el que ha calificado las nuevas formas de afrontar desde mediados del XII ciertas situaciones de conflicto, esto es, el planteamiento de soluciones negociables, como indicios de politización de las relaciones de poder; BISSON, T., La crisis del siglo XII. El poder, la nobleza y los orígenes de la gobernación europea, Barcelona, 2010, p. 545-594. 
ciones de poder que continuarán a lo largo de la Baja Edad Media. Seguir la evolución del campo semántico de lo político, partiendo del propio vocablo, identificando palabras afines y valoraciones en contextos diversos, puede ser un buen método para descubrir los momentos en los que la sociedad medieval se vio más o menos politizada. No podemos en tan breve espacio reunir e interpretar toda la información lingüística que se requiere para tal tarea, por ello, este trabajo es un punto de partida. Además, la unidad de la cultura latina en Occidente, previa a la extensión de las lenguas vulgares, nos obliga a centrar primero el recorrido en el siglo XII, que es, precisamente, el momento en que parece detectarse este cambio. Pero, siguiendo la perspectiva conceptual apuntada en el primer apartado, es preciso antes que nada deslindar la noción medieval del concepto actual de política.

\subsection{Deconstruir el concepto actual de politica}

Si partimos de la actualidad, hemos de indicar que, en el siglo XXI, asistimos a una nueva etapa en la evolución de la noción de política, aún difícil de determinar, pero que ha sido calificada por los estudiosos del concepto como 'post-política'. La política está hoy casi vaciada de contenido y diversos factores han contribuido a ello: la inflación de su uso en contextos dispares o contradictorios (las 'políticas', en plural); el desprestigio de la actividad política y de los políticos; la creciente fuerza de los grupos de interés privados, que deciden por encima del interés público; la incapacidad política para evitar las crisis económicas; la falta de adecuación al nuevo mundo globalizado... Los valores cívicos asociados a lo político están siendo sustituidos por valores particulares ligados a identidades diversas y a grupos comunitarios alimentados por una fuerte carga emotiva ${ }^{36}$. Tal deriva se fue gestando al hilo de los acontecimientos del siglo $\mathrm{xx}$, cuyos inicios marcaron una nueva resignificación del concepto de política (la llamada, por entonces, realpolitik, es reflejo de ello). Desde el primer tercio del siglo XX, la política sería percibida cada vez más desde las nociones de poder y dominio $^{37}$, lo cual no deja de llamar la atención puesto que, como veremos, el concepto de política se había ido construyendo, primariamente, en oposición al poder coercitivo. Este giro vino a trastocar algunos de los significados impulsados durante el siglo XIX. En España, las primeras décadas del siglo XIX supusieron otro momento intenso de politización en la socie-

\footnotetext{
36 Javier Fernández Sebastián alude a la actual "emocionalización de la política": ver su artículo «Política» en FERNÁNDEZ SEBASTIÁN, J., Y FRANCISCO FUENTES, J. (dirs.), Diccionario político y social del siglo XX español, pp. 964-967.

37 Ibídem, pp. 948-949.
} 
dad, reflejado en la creación de nuevos términos afines y variantes, hasta el punto de que se llegó a hablar de "políticomanía"38. Frente a la política entre Estados (identificada por la política exterior), la política expresada en la administración (derivada de su equivalente 'policía') y la política de gabinete del siglo XVIII, ligada al mundo cortesano, la política es descubierta por amplias capas de la sociedad que reclaman una participación en los mecanismos de gobierno. Se instala el pluralismo de ideas sobre el modelo de sociedad y de gobierno, las ideologías (palabra que también fue introducida en esta época) y la política paulatinamente se "desteologiza" (en España, más lentamente $)^{39}$. Hacer política equivale a participar en el diseño de una sociedad que pedía transformaciones en un sentido democrático. Pero, al mismo tiempo, se irán extendiendo valoraciones negativas (contra los políticos profesionales, contra esa participación de las clases populares en política, etc.,) desde ámbitos incluso opuestos y, paralelamente, se idean estrategias de despolitización que tendían a ahondar la brecha entre lo público y lo privado, entre individuo y sociedad, entre sociedad política y sociedad civil. A pesar de todo, muchos de los significados tradicionales (forjados desde la Edad Media, y desde las lecturas de la Antigüedad) se mantendrán durante el siglo XIX, pues la política todavía tenía en cuenta el buen gobierno (otra cosa era la realidad pragmática, que fomentaba el desprestigio), la moral cívica unida a lo público, es decir, todavía no se había desligado enteramente de la ética ${ }^{40}$.

Pero, entre fin de siglo y primer tercio del siglo xx, como hemos indicado, las concepciones sobre la política giran hacia el campo del poder y del dominio. Aquí la obra de Max Weber resulta decisiva, y la de otros autores alemanes, como Carl Schmitt, y su teoría sobre la política como perpetuo antagonismo de 'amigo/enemigo', que se extiende a cualquier campo de la actividad humana. La política, con Weber, se convierte en la forma de ejercer legítimamente la fuerza, cuyo monopolio reside en el Estado. En consecuencia, la política solo puede desarrollarse en el Estado: es el poder de Estado. Los marxistas también asumieron esta idea, pues identificaban

38 Término atribuido a Larra; FERNÁNDEZ SEBASTIÁN, J., «Política», en Fernández Sebastián, J., y Francisco Fuentes, J. (dirs.), Diccionario político y social del siglo XIX español, p. 540.

39 Ibídem, p. 540.

40 En inglés, además de 'politics', existe 'policy' y 'polity', que conservan significados relativos a las políticas públicas y el buen gobierno (MATTEUCCI, N., El Estado moderno. Léxico y exploraciones, Madrid, 2010, p. 313). En castellano, el término tradicional 'policía', referido a la buena administración, se aplica hoy solo a la seguridad interior. En el siglo XV, por ejemplo, por "policía política" hubieran entendido algo muy distinto a lo que entendemos hoy. 
igualmente política/poder, aunque con una valoración opuesta: en la nueva sociedad sin clases, al quedar abolido el Estado, no habría ni poder ni política $^{41}$.

\subsection{La fase incipiente de 'politización' en la Edad Media: el siglo XII}

Todas estas evoluciones semánticas han repercutido en la elaboración de los análisis históricos, e influido en la forma de estudiar la historia política. Quizá el declive de este ámbito histórico, el de la historia política, tenga mucho que ver con este cambio semántico, declive no del todo superado por la llamada 'nueva historia política', construida, básicamente, como historia del poder (entendido este según las distintas teorías del siglo $\mathrm{XX}$ (2) $^{42}$ Estamos de acuerdo con Thomas Bisson cuando advierte de que, si se asume que todo poder es político (o que la política equivale a cualquier relación de poder), entonces, el poder político existiría como un continuo universal que quedaría fuera del análisis histórico. Sería preciso asumir la idea de que no todo poder ni todo gobierno son políticos y, de ese modo, asomaría la historicidad de lo político. Entre finales del IX y mediados del XII, los señores o los reyes/ príncipes-señores 'gobernaban' de alguna manera sobre sus vasallos, pero lo hacían desde la cultura señorial y aristocrática. Esto es, una cultura basada en la violencia y en la voluntad señorial; en el parentesco, la herencia, el patrimonio; en los rituales, entre los que se incluían fórmulas de consejo o de consulta aprobatorias. No lo hacían, o solo comenzaban a hacerlo, desde la cultura 'política', basada en la toma de decisiones en asamblea, o en la búsqueda de soluciones negociadas a los conflictos, en fórmulas de pacificación en las que verdaderamente fuera plausible plantear posiciones contrarias que pudieran llegar a armonizarse. Y aunque la noción de orden público no se había perdido del todo, no era operativa, y la 'utilidad pública o común' todavía estaba lejos de constituir de forma generalizada la meta de todo orden

${ }^{41}$ Sobre estos cambios semánticos que orientan la política hacia el poder, ibídem, pp. 324-331.

42 Resume BENIGNO, F., Las palabras del tiempo, pp. 175-198, la construcción teórica y conceptual de la noción de poder, en la segunda mitad del siglo xx: las formas de legitimidad del poder en Weber; la dinámica amigo/enemigo de Schmitt; el poder en la lucha de clases; el poder institucionalizado derivado de las teorías funcionalistas; el poder como reglas del juego en diversos campos; el micropoder o el biopoder de Foucault; el poder como una relación y no como algo que se posee; el poder comunicativo, en su dimensión simbólica, en Bourdieu, entre otros, o como acción colectiva del grupo, en Hannah Arendt, o en la esfera pública, con Habermas. De todos estos aportes teóricos se podrían citar referencias historiográficas aplicadas a la historia medieval, que obviamos por falta de espacio. 
social $^{43}$. Si se admite que lo político tiene historia, se puede determinar el proceso de transformación de esa cultura de señorío en otro tipo de cultura que puede calificarse de 'política'44, acorde con el proceso de politización. Esa cultura política es indicativa, a su vez, de otros cambios fundamentales producidos entre los siglos XII y XIII ${ }^{45}$.

Es a mediados del siglo XII cuando los escritores medievales realizan los primeros intentos serios de pensar su mundo en términos de gobierno ${ }^{46} \mathrm{y}$ para ello recurren al vocabulario antiguo. Juan de Salisbury es el caso más emblemático, uno de los primeros autores en emplear el vocablo 'política' en varias de sus formas latinas ${ }^{47}$. La palabra resultaba ya conocida puesto que

43 BISSON, T., La crisis, pp. 37-47, critica las posiciones de Weber, cuando este plantea que en cualquiera de las formas de poder legítimo existen conductas y cargos de naturaleza política, lo cual no se concilia con la terminología ni la práctica del poder en el siglo XII. A juicio de este historiador, "un estudio histórico del poder parece irremediablemente atado al modernismo", puesto que el propio concepto de 'poder' pertenece a las ciencias sociales.

44 Indicios de cambios en la cultura señorial serían la adopción de fórmulas institucionalizadas como la rendición de cuentas, el desempeño de cargos, así como la presencia en las cortes, tribunales, consejos o asambleas, de discursos menos ritualizados y más argumentativos y polémicos (esto es, verdaderamente dialógicos); ibídem, pp. 555.

45 Entre otros, la adopción, tanto en ámbito rural como en los nuevos espacios urbanos, de fórmulas de interacción más estables o institucionalizadas o la implicación de la comunidad en empresas colectivas para defender sus fines sociales (ibídem, p. 553). Bisson analiza, además, las asambleas de paz y tregua en Cataluña o la "crisis" de la Carta Magna como "experimentos políticos" en los que se aprecian ya algunas formas nuevas de resolución de los conflictos (ibídem, pp. 560-594).

46 La cuestión de la emergencia de la politización en el siglo XII resulta clave para comprender la tesis de Bisson sobre el inicio de la gobernación en Europa. En ese sentido, valora los intentos que realiza Salisbury de nombrar la gobernación, aunque los considera todavía bastante rudimentarios (ibídem, p. 551).

47 Jean-Philippe Genet realizó un gran esfuerzo metodológico en un breve análisis sobre el vocabulario político en el Policraticus (libros I-VII), utilizando el programa lexicométrico hiperbase, tratando de salvar las dificultades de uso con textos latinos (que él mismo indica). El resultado es un listado de 82 palabras que él considera como vocabulario político, aunque algunas, a priori, no tengan un sentido político (como ciertas virtudes o vicios). Genet se centra en los términos princeps y rex y, en menor medida, en tirannus. El valor de su estudio reside en evidenciar la relevancia del vocabulario de origen antiguo, de 'matriz romana'. Destacan, significativamente, las agrupaciones léxicas a las que da lugar la palabra publicus, entre ellas las que tienen que ver con la Res publica (GENET, J-P. «Le vocabulaire politique du Policraticus de Jean de Salisbury: el prince et le roi», en Aurell, M. (dir.), La cour Plantagenêt (1154-1204), Poitiers, 2000, pp. 187-215, pp. 213-214 para publicus). Sorprende, sin embargo que no aparezca en ese listado la palabra politica y sus formas. Según la lista de palabras del Policraticus que ofrece Monumenta informatik, se cuantifican 11 casos de empleo de politica en seis variantes: politica (2), politicae (3), politicam (2), politici (1), politicorum (2), politicum (1). La edición seguida es la de Migne (1855, PL 199), pero puede cotejarse con las ediciones de Webb (Oxford, 1909) y Keats- 
aparecía en obras destacadas de la tardoantigüedad que, aun con las limitaciones de la época, no habían dejado de leerse. Agustín de Hipona la anotó en De civitate Dei, después de cuestionar a los dioses antiguos, cuando dice: «Nunc propter tres theologias, quas Graeci dicunt mythicen physicen politicen». El adjetivo en sí quiza no dijera mucho sobre su significado, pero lo destacado es que Agustín aclaraba la palabra griega con su equivalente latino: «Latine autem dici possunt fabulosa naturalis civilis ${ }^{48}$. Siendo 'civil' sinónimo de 'político', la palabra se volvía más familiar. En las obras de un autor romano que no dejó de leerse en los primeros siglos medievales, Cicerón, se encuentran también estos sinónimos, y otros, como 'populare', en un contexto semántico que apuntaba a reflexiones sobre la sociedad ${ }^{49}$, reflexiones pensadas por los llamados «politici philosophi» ${ }^{50}$.

Más destacado es otro autor coetáneo de Agustín de Hipona. Macrobio escribió en torno a 430 los Commentarii in somnium Scipionis, escrito que recogía y comentaba, a su vez, un texto que Cicerón incluyó en su De republica (libro VI), obra conocida, precisamente, gracias a estos comentarios. La obra se difundió ampliamente en la Edad Media (más de 230 manuscritos conservados), indicativa de su influencia ${ }^{51}$. Macrobio legó, desde los autores antiguos (Cicerón, Plotino, Porfirio) a los autores medievales uno de los tópicos más importantes que nutrirán el campo semántico de la noción de política en la Edad Media, el de las virtudes políticas. En su obra se leía que sin el

Rohan (CCCM, CXVIII, 1993). Consúltese BÄNZIGER, M., Monumenta Informatik, búsqueda 'politic*' en Ioannes Saresberiensis, http://monumenta.ch/latein/advwortliste.php? suchbegriff $2=$ politic * $\&$ binary $=\&$ modif $=\&$ domain $=\& l a n g=0 \&$ tabelle $=$ Ioann es_Saresberiensis\&id=Ioannes\%20Saresberiensis,\%20Polycraticus\&kkwlaus=wl_id\& von=advsuchen\&suchbegriff=politic $*$ target $=($ Consulta: $2 / 6 / 2014)$.

48 «Nunc propter tres theologias, quas Graeci dicunt mythicen physicen politicen, Latine autem dici possunt fabulosa naturalis civilis, quod neque de fabulosa, quam et ipsi deorum multorum falsorumque cultores liberrime reprehenderunt, neque de civili»; Agustín de Hipona, De Civitate Dei, L. 6, 12. La transcripción corresponde a un manuscrito del siglo XII: Engelberg, Stiftsbibliothek: Cod. 17, 90v.

49 Se refiere a los «Graecis politici philosophi» en De Oratore, 3, 109. Cicerón empleaba el término y sus formas directamente en griego: «Nam cum sic hominis natura generata sit, ut habeat quiddam ingenitum quasi civile atque populare, quod Graeci $\varpi \quad o ́$ vocant, quicquid aget quaeque virtus, id a communitate et ea, quam exposui, caritate ac societate humana non abhorrebit, vicissimque iustitia, ut ipsa se fundet in ceteras virtutes», Cicero, De Finibus Bonorum et Malorum, V, 66 (Th. Schiche, Stuttgart, 1915). Un ejemplo manuscrito de esta obra de los siglos X-XI en Biblioteca Apostolica Vaticana, Pal. lat. 1513.

50 Isidoro, en cambio, no utiliza la palabra 'politica', ni en griego. Se refiere a la filosofía política como 'civil' (Etymol. II, 24, 16).

51 RAVENTÓS, J., «Introducción» a su traducción de Macrobio, Comentarios al Sueño de Escipión, Madrid, 2005, pp. 9-10. 
desarrollo de estas no era posible ni para el ser individual, ni para la comunidad alcanzar la felicidad ( his civium salutem gubernant»). Interpretado según la creencia cristiana suponía no poder alcanzar tampoco la salvación eterna. De este modo, de la mano de estos textos, a mediados del XII (y ya antes, aunque con menor amplitud), se empezaba a leer que toda comunidad humana posee un fin político y que ese fin político se corresponde con el desarrollo de ciertas virtudes propias de la condición humana ${ }^{52}$ : la prudencia, la templanza, la fortaleza y la justicia, cada una de las cuales lleva otras ciertas virtudes o capacidades asociadas. La definición cristiana de la virtud ya no bastaba para pensar los fines de la sociedad. Si el ser humano, considerado un animal social, obra conforme a estas virtudes, no solo se regirá a sí mismo, sino a la república. La política se define como acción en la comunidad, y se identifica con sus límites morales. La consecuencia es que si se sobrepasan esos límites, no existe ya la política, sino el dominio. El texto de Macrobio, que tanta influencia tendrá ${ }^{53}$, es el siguiente:

Quattuor sunt inquit quaternarum genera virtutum. Ex his primae politicae vocantur, secundae purgatoriae, tertiae animi iam purgati, quartae exemplares. Et sunt politicae hominis, quia sociale animal est. His boni viri rei publicae consulunt, urbes tuentur his parentes venerantur, liberos amant, proximos diligunt. His civium salutem gubernant; his socios circumspecta providentia protegunt, iusta liberalitate devinciunt. Hisque sui memores alios fecere merendo. Et est politici prudentiae ad rationis normam quae cogitat quaeque agit universa dirigere ac nihil praeter rectum velle vel facere humanisque actibus tamquam divinis arbitriis providere. Prudentiae insunt ratio, intellectus, circumspectio, providentia, docilitas, cautio. Fortitudinis animum supra periculi metum agere nihilque nisi turpia timere, tolerare fortiter vel adversa vel prospera. Fortitudo praestat magnanimitatem, fiduciam, securitatem, magnificentiam, constantiam, tolerantiam, firmitatem. Temperantiae nihil adpetere paenitendum, in nullo legem moderationis excedere, sub iugum rationis cupiditatem domare. Temperantiam secuntur modestia, verecundia, abstinentia, castitas, honestas, moderatio, parcitas, sobrietas, pudicitia. Iustitiae servare uni cuique quod suum est. De iustitia veniunt innocentia, amicitia, concordia, pietas, religio, affectus, humanitas. His virtutibus vir bonus primum sui atque inde rei publicae rector efficitur, iuste ac provide gubernans humana, non deserens ${ }^{54}$.

52 «Virtus est habitus mentis bene constitute», definición tomada de Cicerón que aparece en una suma de derecho del siglo XII: La Summa 'Iustiniani est in hoc opere', ed. Pierre Legendre, Frankfurt del Meno, 1973, p. 23.

53 Macrobio será la fuente más empleada por los teóricos del regimiento de las ciudades en Italia en el siglo XIII: VIROLI, M., De la política a la razón de Estado. La adquisición y transformación del lenguaje político (1250-1600), Madrid, 2009, pp. 48-51.

54 MACROBIO: Commentaria in Somnium Scipionis, 1, VIII, 14-17. Otras menciones refuerzan la misma idea: «Si ergo hoc est officium et effectus virtutum, beare, constat 
La originalidad de Macrobio reside en que amplificó la relevancia de estas virtudes políticas respecto a sus referentes neoplatónicos, ya que para él eran superiores a los otros tipos de virtud ${ }^{55}$. Además, al afirmar la capacidad de estas virtudes para facilitar la felicidad eterna (siguiendo a Cicerón), Macrobio aportaba a los autores medievales un argumento para valorar la vida política, esto es, la vida secular, en la misma medida que la vida contemplativa. La vida política, en la mentalidad medieval, se asociaba así con la vida activa que desarrollaba el ser humano en sociedad o comunidad. Y esta podía alcanzar un valor por sí mismo para lograr la salvación.

Gracias a la gran difusión y al interés que despertó esta obra ${ }^{56}$, los argumentos de Macrobio sobre las virtudes en la vida política sostuvieron con eficacia el recuerdo de la palabra 'política' y sus derivados, pues aparece cada vez más en textos del siglo XII. Sin embargo, no deberíamos limitarnos a los textos, sino que habría que tener en cuenta igualmente la difusión oral; no en vano es la época del gran impulso pedagógico y filosófico y estos textos formaban parte del catálogo de autores sobre los que estos nuevos filósofos polemizaban en las escuelas ${ }^{57}$. Un transmisor importante de las ideas de Macrobio fue Pedro Abelardo, que se refería también a las virtudes 'políticas' en sus obras ${ }^{58}$. Así por tanto, es difícil hacerse idea de la frecuencia de su uso,

autem et politicas esse virtutes: igitur et politicis efficiuntur beati» (1, VIII, 28). Y, refiriéndose a Escipión: «In re enim una politicarum virtutum omnium pariter exercet officium» $(1, X, 3)$; «sed ut in castris locato ac sudanti sub armis primum virtutes politicae suggeruntur» (2, XVII, 10).

55 Lo ha destacado SACCENTI, R., «Quattro gradi di virtù: il modello etico dei Commentarii di Macrobio nel XII secolo», Medioevo. Rivista di Storia della Filosofia Medievale, 31 (2006), pp. 69-101, y MELCHIONNA, A., Macrobio e la filosofia: i Commentarii in Somnium Scipionis, Salerno, 2010, p. 88-97; http://elea.unisa.it:8080/jspui/ handle/10556/149 (Consulta: 25/5/2014).

56 Las diferentes lecturas del manuscrito BNF, Ms. Latin 6370 (transcripción en Monumenta informatik), así lo atestiguan: copiado en la abadía de Saint-Martin de Tours ca. 820, y corregido ca. 840, por Lupo de Ferrières, tiene glosas de la época (de Heiric de Auxerre) y de lectores anónimos del XII y del XV. A mediados del XVI se encontraba en la biblioteca real de Carlos IX; descripción en http://gallica.bnf.fr (Consulta: 3/6/2014).

57 Yves Sassier resalta el hecho de que fueron los intelectuales del XII los que retomaron la palabra 'política' y no los del siglo XIII, cuestión a la que no han dado la importancia debida los historiadores de las ideas; SASSIER, Y., Royaté et idéologie au Moyen Âge, París, 2002, p. 252.

58 «Quaternariam virtutum distinctionem attendas, alias videlicet politicas...», ABELARDO, P., Diálogo entre un filósofo, un judío y un cristiano, (ed. bilingüe), est. trad. y notas, Silvia Magnavacca, Buenos Aires, 2003, p. 202. Sassier ha destacado el papel de Abelardo como impulsor de las nociones de res publica o de utilitas communis: Abelardo supo ver en las reflexiones políticas de los filósofos antiguos un modelo que conectaba con su ideal de comunidad cristiana: utilidad común, primado de la comunidad, caridad y fraternidad (véase su artículo SASSIER, Y., «Pierré Abélard et la cité 
pero debió ser notable, considerando este papel de las escuelas, en donde la teoría sobre la virtud de Macrobio suscitaba debates y controversias. Por ejemplo, un discípulo de Abelardo, Simon de Tournai, no apoyaba la idea de que las virtudes políticas, o cívicas, bastaran para salvarse, ya que, en ese caso, también judíos y musulmanes podrían salvarse ${ }^{59}$. En las escuelas, además, se aprendía también que la política era una parte de la filosofía práctica, tal y como figuraba en la clasificación aristotélica. En este sentido, la explicación que da Hugo de Saint-Victor en el Didascalicon (ca. 1128) ${ }^{60}$, por tratarse de un manual básico para la enseñanza, consolidaba nuevos sinóminos y campos de aplicación (como la vinculación con las ciudades y con todo aquello que administra la utilidad común):

Practica dividitur in solitariam, privatam et publicam; vel aliter, in ethicam, oeconomicam et politicam; vel aliter, in moralem et dispensativam et civilem. Una est solitaria, ethica et moralis; una rursum, privata, oeconomica et dispensativa. Eademque publica, politica atque civilis. Oeconomus interpretatur dispensator. Inde oeconomica dicta est dispensativa. Polis Graece, Latine civitas dicitur; inde politica dicta est, id est, civilis [...]. Publica est "quae reipublicae curam suscipiens, cunctorum saluti suae providentiae sollertia, et iustitiae libra, et fortitudinis stabilitate, et temperantiae patientia medetur". Solitaria igitur convenit singularibus, privata patribus familias, politica rectoribus urbium. [...] "Civilis dicitur per quam totius civitatis utilitas administratur"61.

Otra vía de difusión destacada procede del mundo del derecho. Y es que el texto de Macrobio fue incluido por los primeros glosadores del derecho justinianeo entre los tópicos que fundamentaban la idea de justicia. De este modo, la palabra era incorporada al cúmulo de nociones de una cultura jurídica en formación. Aparece, por ejemplo, en una suma escrita por un comentador francés anónimo, en el libro primero, «De iusticia et iure»: al enumerar las clases de virtudes, aclara el sentido de la palabra 'politice', con su sinómino civil («Prime politice, idest civiles vocantur»), y antes de citar el segundo tipo de virtud introduce otra aclaración: «Politice virtutes pertinent

des philosophes de l'antiquité paienne», y otros reeditados juntamente con el título Structures du pouvoir, royauté et res publica: (France, IXe - XIIe siècle), Rouen, 2004.

59 Cit. VIROLI, M., De la politica..., p. 54.

60 Sobre la importancia de Hugo de San Víctor como difusor de 'lo político' dentro del sistema de clasificación del conocimiento en Aristóteles, NEDERMAN, C. J., Medieval Aristotelism and its Limits: Classical Traditions in Moral and Political Philosophy, 12th15th Centuries, Aldershot, 1997, p. 75.

61 Didascalicon, XIX, 759-760. San Víctor utiliza el Commentaria in Porphyrium de Boecio. SANTO VICTORE, Hugo de, Didascalicon, de studio legendi (El afán por el estudio), Muñoz, C., y Arribas M ${ }^{a}$ L., (ed. y trad.), Madrid, 2011, p. 90. Guillermo de Conches, en la escuela de Chartres, también recogía esta clasificación, aplicando el término 'político' a la comunidad urbana (SASSIER, Y., Royauté, p. 254). 
illis quibus res publica traditur ad gubernandum ${ }^{62}$. Las virtudes políticas son propias del ser humano social, esto es, político («Politice sunt hominis quia sociale animal est»), y, de forma específica, de aquellos que se dedicarán a gobernar la república. Sin entrar en la cuestión de qué se entiende por gobierno en esta época, ni de a quién o quiénes se atribuye esa capacidad de gobernar, interesa retener las palabras que van rodeando y formando el campo léxico de 'política', pues todas ellas irán dotando de contenido semántico al concepto que está formándose: 'civil', 'urbano', 'virtud', 'justicia', 'derecho', 'res publica', 'gobierno', 'administración', 'utilitas': no es la historia de la palabra lo que importa en último término, sino la historia del concepto. Resulta relevante, además, conocer los agentes que incorporan este vocabulario a sus discursos, además de los destinatarios: en este caso, el hecho de que interese a ese nuevo grupo que son los juristas muestra cómo lo 'político' conecta con el nuevo orden que se estaba dibujando mediante el desarrollo del derecho común y de la cultura a él asociada ${ }^{63}$.

La frecuencia de uso se refleja también en la variedad de formas nuevas. Hay que tener en cuenta que la cultura romana empleaba la palabra como un cultismo y frecuentemente la escribía en griego. Salvo en el caso de Cicerón, su empleo como adjetivo era muy raro ${ }^{64}$. En los textos anteriores ya vimos que el calificativo se asocia con la virtud; con Juan de Salisbury, la palabra aumenta en frecuencia y en variedad de formas, calificando nuevos objetos. Parece como si Salisbury hubiera dado un sentido más político a las enseñanzas recibidas de sus maestros ${ }^{65}$. En la

62 La Summa 'Iustiniani, p. 23 (Pierpont Morgan Library, ms. 903, fol. 2rb). El texto es del siglo XII, pero el manuscrito que conserva la suma es del siglo XIII. Cita a este jurista, BISSON, T., La crisis, p. 551.

63 Carlos Garriga describe los rasgos de esta cultura jurisdiccional o jurisdiccionalista, y sus formas institucionales, que sustentan un modelo político distinto al que proponen los defensores de la teoría de la génesis del Estado moderno: GARRIGA, C., «Orden jurídico y poder político en el Antiguo Régimen», Istor, IV, 16 (2004), http://www. istor.cide.edu/archivos/num_16/dossier1.pdf (Consulta: 3/5/2014).

64 Matteucci afirma que, 'político/a' como adjetivo, irrumpe en la Edad Media con la traducción al latín de la Política de Aristóteles por Guillermo de Moerbecke (ca. 1260), MATTEUCCI, N., El Estado moderno, p. 319; si bien, como vemos, aparece ya en estas obras del XII.

65 Abelardo y Guillermo de Conches, entre otros, fueron maestros de Salisbury. Sobre el impulso de las nociones de bien común y de utilidad común en Abelardo y Salisbury, véase SASSIER, Y., «Bien commun et utilitas communis au XII siècle, un nouvel essor?», Revue française d'histoire des idées politiques, $32,2^{\circ}$ sem. (2010), pp. 245-258; cit. por SASSIER, Y., «Le prince, ministre de la loi? (Jean de Salisbury, Policraticus, IV, 1-2)», en Oudart, H., Picard, J-M. y Quaghebeur (eds.), Le prince, son peuple et le bien commun. De l'Antiquité tardive à la fin du Moyen Âge, Rennes, 2013, p. 129, n. 15. Sassier menciona el pasaje que recogemos en la tabla, Policraticus, 1, 3 como típicamente "abelardiano" (n. 16). 
TABla 1: Menciones de 'politica' y sus formas en Policraticus de Juan de Salisbury

\begin{tabular}{|c|c|}
\hline $\begin{array}{l}\text { Philosophi gentium, iustitiam, quae politica dicitur, } \\
\text { praeceptis et moribus informantes, cuius merito } \\
\text { respublica hominum subsistit et viget, unumquemque } \\
\text { suis rebus et studiis voluerunt esse contentum, urbanis } \\
\text { et suburbanis, colonis quoque vel rusticis sua singulis } \\
\text { loca et studia praescribentes. Sollicitudo singulorum et } \\
\text { omnium utilitati publicae serviebat. Naturae, laboris, et } \\
\text { industriae fructum unusquisque recipiebat ex merito ( } 1 \text {, } \\
\text { 3). }\end{array}$ & $\begin{array}{l}\text { Política como } \\
\text { justicia. } \\
\text { Filósofos. }\end{array}$ \\
\hline $\begin{array}{l}\text { Sane facilius est utrumque involvi, quam alterum } \\
\text { istorum expediri. Utrius tamen culpa sit gravior, non } \\
\text { facile dixerim. Haec de his quae in politica constitutione } \\
\text { Plutarchi, vicem animae obtinent }(5,5) \text {. }\end{array}$ & $\begin{array}{l}\text { Constitución } \\
\text { política ideada por } \\
\text { Plutarco. }\end{array}$ \\
\hline $\begin{array}{l}\text { Tu vero quidvis rectissime geres, si non recesseris a te } \\
\text { ipso. Si primum te composueris, si tua omnia disposueris } \\
\text { ad virtutem, recte tibi procedent universa. } \\
\text { Politicae constitutionis maiorum vires tibi exscripsi, } \\
\text { cui si obtemperas, Plutarchum vivendi habes auctorem. } \\
\text { Alioquin praesentem epistolam testem invoco, quia in } \\
\text { perniciem imperii non pergis, auctore Plutarcho }(5,1) \text {. }\end{array}$ & $\begin{array}{l}\text { Constitución } \\
\text { política descrita por } \\
\text { Plutarco. }\end{array}$ \\
\hline $\begin{array}{l}\text { Sequuntur eiusdem politicae constitutionis capitula in } \\
\text { libello qui inscribitur Institutio Traiani }(5,2) \text {. }\end{array}$ & $\begin{array}{l}\text { Constitución } \\
\text { politica descrita por } \\
\text { Plutarco. }\end{array}$ \\
\hline $\begin{array}{l}\text { Rem politicam legitur Socrates instituisse, et in eam } \\
\text { dedisse praecepta, quae a sinceritate sapientiae, quasi } \\
\text { quodam fonte naturae manare dicuntur. Hoc autem in } \\
\text { summa colligitur, ut quae in republica humiliora sunt, } \\
\text { maiorum officio diligentius conserventur }(6,25) \text {. }\end{array}$ & $\begin{array}{l}\text { Cosas políticas o } \\
\text { república ideada } \\
\text { por Sócrates. }\end{array}$ \\
\hline $\begin{array}{l}\text { Cui Papinianus, vir quidem iuris experientissimus, et } \\
\text { Demosthenes, orator praepotens, videntur suffragari, } \\
\text { et omnium hominum subiicere obedientiam, eo quod } \\
\text { lex omnis inventio quidem est, et donum Dei, dogma } \\
\text { sapientum, correctio voluntariorum excessuum, civitatis } \\
\text { compositio, et totius criminis fuga; secundum quam } \\
\text { decet vivere omnes, qui in politicae rei universitate } \\
\text { versantur }(4,2) \text {. }\end{array}$ & $\begin{array}{l}\text { Cosas politicas. Los } \\
\text { que se dedican a } \\
\text { ello. Ley. }\end{array}$ \\
\hline
\end{tabular}


Quo quidem aliquid esse utilius ad scientiam aspiranti, facile non crediderim, praeter observantiam mandatorum Dei, in qua singularis et unicus indubitanter est philosophandi profectus. Sic tamen omnia legenda sunt, ut eorum aliqua cum lecta fuerint, negligantur, reprobentur nonnulla, aliqua videantur in transitu, ne sint omnino incognita: sed prae omnibus maiori diligentia insistendum est, quae aut politicam vitam, sive in iure civili, sive in aliis Ethicae praeceptis instituunt, aut procurant corporis aut animae sanitatem $(7,9)$.

Dicitur autem quia tyrannus est, qui violenta dominatione populum premit; sed tamen non in populo tantum, sed in quantavis paucitate, potest quisque suam tyrannidem exercere. Nam etsi non populo, tamen quatenus quisque potest, dominatur. Non enim de his institutus est sermo, qui sunt omnino animi defaecati, et subiectione continua gaudentes, alicui in vita praeesse refugiunt. Vita potius politicorum excutienda est. Quem mihi dabis inter illos, qui non velit vel unum potentia anteire? $(7,17)$.

Apostolorum tamen et familiaritatis intimae privilegium astruit, quod verbum fidei boni operis perseverantia illustravit, cum philosophi evanuerint, non modo in cogitationibus, sed operibus suis. Scripsit libros plurimos, et politici hominis merita contemplationum repressit, et contemplationis acumen actionis necessitas non exstinxit $(7,5)$.

At philosophus virum politicum mittit ad apes, ut ab illis suum discat officium $(6,24)$.

Novi tamen regulam veritatis, qua mihi constat, quia religio munda et immaculata apud Deum et patrem, haec est, visitare pupillos et viduas in tribulatione eorum, et immaculatum se custodire ab hoc saeculo. Haec autem politicorum omnium est: et bene cum istis agitur, si eam fideliter servant $(7,23)$.
Vida política.

Lecturas que instruyen en ello: derecho civil, Ética.

Vida. Políticos. Tiranía.

Hombre político. Vida contemplativa/ vida activa.

Tabla 1 se han clasificado recogidas en el Policraticus (ca. 1159) de Juan de Salisbury y sus relaciones semánticas ${ }^{66}$ :

Con Salisbury se abren nuevas relaciones semánticas: lo político se identifica con la comunidad humana sujeta a normas, y con las normas o leyes

66 Ocurrencias obtenidas de la búsqueda en Monumenta informatik, citada anteriormente. Otro caso en Metalogicus (Migne, 1855, PL 199): «sed omnes simul urbes et politicam vitam totam aggreditur», en el sentido de 'vida política'. 
que conforman esa sociedad (politicae constitutionis): en suma, es la res publica de modelo corporativo que propone según la Institutui Traiani, y que atribuye a Plutarco (que, como se sabe, quizá inventara él mismo) ${ }^{67}$. Es especialmente relevante la identificación de esa comunidad política con la justicia (está implícita la dicotomía justicia divina/justicia humana, siendo la humana, la que recibiría el nombre de 'política'), lo cual muestra conexiones con la cultura jurídica. Lo político, en el sentido de 'cosa pública' (politicae rei) es, sobre todo, un tipo de vida (politicam vitam), según la dicotomía vida activa/vida contemplativa. Por primera vez aparecen, de forma extensa, referencias a 'los políticos' (virum politicum, politici hominis); pero su sentido es genérico, son todos los que se dedican al tipo de vida política (vita politicorum). Salisbury emula así a Sócrates, Platón, Plutarco y los demás filósofos antiguos con este ejercicio de filosofía práctica. De las enseñanzas de los filósofos antiguos, Salisbury retiene ese modelo de organización social sujeta a normas. En ellos encuentra preceptos útiles que sirvan de guía a los hombres dedicados activamente a la vida política. Es decir, preceptos basados en normas de derecho (civil) y morales. Los que se dedican a la vida política deben, además, vivir conforme a la ley. Salisbury identifica a estos políticos con cualquier seglar, dedicado a este tipo de vida, en oposición a los que se dedican a la vida contemplativa o espiritual $(7,23)$. Estos políticos no son solo los que ostentan cargos públicos o los cortesanos. En Policraticus, 7, 17, al aludir a la posibilidad de la tiranía, se ve más claramente. La tiranía también es entendida en un sentido genérico, como la práctica en la que puede caer cualquiera que ejerza un abuso de poder hasta en las cosas más pequeñas. Solo los que tienen un alma pura (renuncian a dominar, dedicándose, se entiende, a la vida contemplativa), están exentos de caer en la tentación de querer preceder a otros en la vida. Los que se dedican a la vida política, -es decir, a la vida del siglo-, los hombres políticos, en cambio, tienden a querer dominar sobre otros ${ }^{68}$. Y aquí aflora su constante preocupación por el

67 Ayegl Keskin cita este pasaje de Policraticus, 1, 3, para ilustrar el modelo de res publica que propone Salisbury, a su entender, un modelo basado en relaciones de reciprocidad entre la esfera temporal y la esfera espiritual y entre los miembros de cada esfera: KESKIN ÇOLAK, A., Nugae Curialium reconsidered: John of Salisbury's court criticism in the context of his political theory, Birmingham, 2012, p. 36, en línea con la tesis de NEDERMAN, C. J. y CAMPBELL, C., «Priests, Kings, and Tyrants: Spiritual and Temporal Power in John of Salisbury's Policraticus», Speculum, 66, no. 3 (1991), pp. 572-590.

68 Puede percibirse la diversidad de matices que presenta la tiranía en la obra de Salisbury, analizando el listado con todas las menciones de tyrannus y tyrannis que reunió VAN LAARHOVEN, J., «Thou shalt NOT slay a tyrant!», en Wilks, M. (ed.), The world of John of Salisbury, Oxford, 1994, pp. 333-341. 
poder: Salisbury parece referirse a la experiencia, al plantear la pregunta de si entre los políticos hay alguno que no quiera dominar sobre otro: «Quem mihi dabis inter illos, qui non velit vel unum potentia anteire?» Así pues, no es el cargo lo que lo define al político, sino su participación en la vida del siglo, su actuación en la sociedad regida por constituciones políticas. Y esta conducta será correcta, si los hombres políticos viven conforme a las leyes y guiados por preceptos morales y de derecho civil, y tiránica cuando, en vez de ello, los hombres políticos pretendan dominar unos sobre otros, tratando de superar en poder -potentia- a los otros (tal y como podía verse en la experiencia que compartían Salisbury y sus lectores cortesanos) ${ }^{69}$.

\section{CONCLUSIÓN}

A la luz de este breve repaso por la aparición, frecuencia y significados en la Edad Media del término 'politica', vale la pena reivindicar la originalidad de la cultura del siglo XII para impulsar un vocablo antiguo cuyo contenido semántico se adaptará a nuevas experiencias en las relaciones sociales y de poder. Aunque de forma incipiente, en torno a lo político se estaba formando un campo semántico que conviene reconstruir desde una perspectiva conceptual, y ver en qué medida entra en conexión con esas experiencias nuevas, que podríamos calificar de 'políticas', y que difieren de los modos de ejercer el poder según la cultura del dominio. Si admitimos que entre los siglos XII y XIII comienza a producirse un fenómeno de politización, que implica también la politización de la cultura, contaremos con un criterio destacado para valorar los cambios institucionales que se producirán en la Baja Edad Media. Podremos entonces detectar en los diferentes territorios momentos similares de politización y de enriquecimiento de esa cultura política en formación, señalar las distintas fases de recepción y de adaptación de significados, cuando las ideas tomadas de textos latinos se traduzcan y vulgaricen $^{70}$. Quedaría por saber hacia adónde apuntan esos cambios. Si nos atenemos a la definición de la política en la época, no parece que la cultura política medieval, tal y como se está dibujando, apunte hacia ese

69 Hay otra posible mención en una de sus cartas: «exigentibus hominum meritis, in polisi mundana». La Epistola Bartholomeo Exoniensi episcopo, datada en febrero de 1169 en MILLOR, W. J. y BROOKE, C. N. L., The Letters of John of Salisbury, vol. 2, The Later Letters (1163-1180), Oxford, 1979, 288, p. 636.

70 La aparición de nuevas formas, como 'politizar', en el sentido de actuar políticamente, actuar en la ciudad, o en la comunidad, solidariamente y en pro de la utilidad común, revelan, tal y como hemos indicado, una nueva fase de cambios (CARRASCO MANCHADO, A. I., «Análisis de las fuentes literarias castellanas»). 
constructo historiográfico que se ha definido como "Estado moderno"71. El sentido de 'politica' en el Policraticus, tal y como se ha mostrado, no es usado, según se ha afirmado, «to denote the institutions of the State» ${ }^{72}$, porque la constitución política de Plutarco/Salisbury agrupa en un mismo sentido la comunidad de sus habitantes, que viven políticamente, y las leyes que rigen esa comunidad. No apunta hacia lo estatal entendido como entidad separada. Y, aunque entre los sinónimos 'politico' se encuentre el de 'público', tampoco sugiere una distinción entre esfera pública y esfera privada, tal y como se entiende para el mundo contemporáneo ${ }^{73}$. Puede decirse que los discursos del siglo XII legaron a los siglos posteriores la noción de "comunidad política" ${ }^{\text {"4 }}$, comunidad también designada como Res publica. No podría hablarse tampoco de sociedad política, entendida esta como grupo de hombres de poder, puesto que 'políticos' son todas las criaturas humanas que forman parte de esa comunidad (exceptuando a las que buscan alejarse de la vida del mundo y, en cualquier caso, Salisbury es probable que esté pensando sobre todo en los varones), no se circunscribe

$\overline{71}$ No compartimos la conclusión de Jean-Philippe Genet, para el cual, la utilización del vocabulario romano por Salisbury es capital para la formación, siglo y medio después, del lenguaje del Estado moderno (GENET, J. P., «Le vocabulaire», p. 200). El problema puede residir en que Genet parece pensar lo político desde las concepciones del siglo Xx (en el transfondo de sus trabajos se perciben las ideas de Weber o de Carl Schmitt). En su artículo «Saint Louis: le roi politique», Médiévales, vol. 34 (1998) pp. 25-34, enfrenta el problema de qué es un rey feudal y qué es un rey moderno. Aun reconociendo por él mismo que la cuestión es anacrónica, su conclusión es que un rey moderno es un "roi de guerre" (p. 26). Sin embargo, el campo semántico de la política en la Edad Media parece incluir la noción de paz, y no la de la guerra. Cabe pensar que la noción de Estado moderno podría estar a punto de ser abandonada por la historiografía: véanse las críticas de SCHAUB, J-F., «La notion d'État moderne est-elle utile? Remarques sur les blocages de la démarche comparatiste en histoire», Cahiers du monde russe, 46 (2005), pp. 51-64.

72 RUBINSTEIN, N., «The history of the word politicus in early-modern Europe», en Pagden, A. (ed.), The Languages of Political Theory in Early-Modern Europe, Cambridge, 1987, p. 41, citando Policraticus IV, 2 y V, 2.

73 Sobre esta dicotomía, también necesitada de reconstrucción conceptual, y su relación con el Estado, es preciso citar el clásico trabajo de CHITTOLINI, G., «Il 'privato', il 'pubblico', lo Stato», en Chittolini, G., Molho, A., y Schiera, P. (eds.), Origini dello Stato. Processi di formazione statale in Italia fra medioevo ed età moderna, Bolonia, 1994. Philippe Buc aclara la oposición aparente 'publicum/privatum' en algunos autores del XII, que en sus comentarios santificaban con referencias bíblicas la comunidad natural existente entre el rey y su pueblo (BUC, P., L’ambiguïté du livre, París, 1994, pp. 323329).

74 Los pensadores del siglo XIV tenían ya formada una noción clara de comunidad política; WATTS, J., The Making of Polities: Europe, 1300-1500, Nueva York, 2009, pp. 132-135. 
a una élite gobernante ${ }^{75}$. En cuanto a la noción de 'cultura política' creo que vale la pena analizarla en el sentido apuntado ${ }^{76}$, un sentido estrictamente vinculado al campo semántico de lo político en la Edad Media (que está aún por estudiar) y a los procesos de politización. Aunque la variedad del discurso historiográfico pueda ofrecer otras diferentes aproximaciones que contribuyan a mantener la vigencia del debate ${ }^{77}$.

75 Ya Claude Gauvard proponía hace unos años sustituir la noción valorada actualmente de 'sociedad política' por 'sociedad cívica', en un sentido extenso que englobara, tanto a las élites como a las clases populares (esto es, a toda la comunidad) en su interacción con el príncipe o monarca: GAUVARD, C., «Introducción», Challet, V., Genet, J.-P., Oliva, H. R. y Valdeón, J. (eds.), La sociedad política a fines del siglo XV en los Reinos ibéricos y en Europa, Valladolid, pp. 11-20.

76 Como fenómeno paralelo, y siempre que no se confunda con la teoría del proceso civilizatorio de Norbet Elias, me parece operativa la expresión "alfabetización política" empleada por François Foronda. Él lo entiende como difusión e integración de la responsabilización gubernativa: FORONDA, F., «El consejo de Jetró a Moisés (Ex. 18, 13-27) o el relato fundacional de un gobierno compartido en la Castilla Trastámara», en Boucheron, P. y Ruiz Gómez, F. (coords.), Modelos culturales y normas sociales al final de la Edad Media, Cuenca, 2009, pp. 110; pero también cuadra a la perfección para designar el proceso de formación y adopción de la cultura política.

77 Cultura política es una noción tomada de la sociología que ha penetrado en el análisis histórico (BERSTEIN, S., «L' historien et la culture politique», Vingtième Siècle. Revue d'histoire, 35 (1992), pp. 67-77) y que vino a sustituir al desprestigiado concepto de 'ideología', aunque está incorporando otros sentidos de la antropología. Véase, por ejemplo, el último dossier sobre Culturas políticas urbanas en la Península ibérica, en Edad Media. Revista de Historia, 14 (2013). 